Volume 16(3) (2019), 224-237

Copyright $\odot 2020$ Equinox Publishing Ltd

Sheffield

http://equinoxpub.com

https://doi.org/10.1558/cam.38920

\title{
Opening up space for compassion in nurses' handover meetings
}

\author{
HARRIET LLOYD ${ }^{1}$, TOM BARTLETT ${ }^{2}$, MICHELLE ALDRIDGE-WADDON ${ }^{3}$, \\ TEREZA SPILIOTI ${ }^{3}$ AND VIRPI YLÄNNE ${ }^{3}$
}

(1) Welsh Government (2) University of Glasgow (3) Cardiff University

\begin{abstract}
In this paper, we complement research into compassion in medical contexts with an analysis of the representation of patients in nursing handovers and the ways in which such practitioner-practitioner interaction can be said to demonstrate and evoke feelings of compassion towards patients. We label such representation as 'Compassion Talk' and suggest that potentially it can complement the information given as part of the standard format for handovers. The analysis is based on instances of non-scripted talk (NST) from three nursing handover meetings from a highly performing Medical Assessment Unit in the UK. In a data-led qualitative analysis, we find that within NST patients are represented in terms that not only make nurses' actions to alleviate their suffering seem possible and necessary, but that also highlight their shared humanity and position the patients as if they are members of the nurses' wider social group. We further demonstrate how NST can be successfully managed by experienced nursing staff and suggest, therefore, that handovers can function not only to pass on information accurately and concisely, but also as a space for nurses to regroup as a community of practice and to relate to their patients in human terms, as a defining principle of the profession.
\end{abstract}

Keywords: communities of practice; compassion talk; data-led analysis; handovers; non-scripted talk; patient safety

\section{Introduction: The tensions between task-focus and compassion}

In this paper we consider the competing pressures on nursing staff, who are increasingly expected to perform to standardised bureaucratic procedures while continuing to behave with humanity and compassion towards the individual patients in their care. The breaking point in such competing demands was brought dramatically to public attention in the UK with the publication of the Francis Report (Francis 2013) into the so-called 'Mid-Staffs Scandal'. Between 400 and 1200 patients died, allegedly as a result of poor care at two UK hospitals run by the Mid Staffordshire NHS Hospital Trust, and the Francis Report attributed the failings in these hospitals in part to low morale amongst nursing staff, with many nurses showing 'a disturbing lack of compassion' towards their patients (Campbell 2013).

While the problems with the Mid-Staffordshire Trust received a great deal of publicity in the UK media, they were seen not as an isolated case but as a particularly salient example of a more widespread problem with its root cause in the bureaucratisation of public healthcare in the UK and a focus on fiscal and organisational concerns over patient welfare, as reported in the response to the Francis Report from the Royal College of Psychiatrists (RCP):

\section{eøuınoxonlıne}


There is a groundswell of opinion that too much business in the National Health Service (NHS) is about completing tasks, meeting objectives, operating within process and financial envelopes, and that not enough is done to ensure that patients feel respected, are treated as individuals and are handled sensitively.

(Royal College of Psychiatrists 2015: 1)

Nor is this situation confined to the UK; a few years previously, healthcare in Australia came under increased scrutiny following a number of high-level failures attributed to an increase in clinical staff taking on managerial responsibility (Iedema 2007: 1). Iedema (2007:7-8) notes that this had led to the production of formalised guidelines, procedures and regulations which aimed to improve the efficiency of healthcare systems. However, as with the Mid Staffs example, these interventions often had the adverse effect of undermining less tangible but ultimately vital aspects of the services they sought to improve, particularly in terms of the expanding range of roles practitioners are expected to fulfil within a complex network of stakeholder relations and the challenges for communication within such 'crowded spaces' (Iedema 2007: 9).

Studies and reports such as these, from clinicians and researchers, point to a common question: how is it possible to reintroduce, or reinforce, compassion within healthcare encounters while maintaining the necessary focus on institutional objectives and procedures? In this paper we take up this question with respect to nursing handover meetings. This marks a significant departure from previous literature within the field of health communication, where research on handovers has tended to focus on the efficient transfer of core information, while discussions of compassion have been based almost exclusively on practitionerpatient interaction in the clinic or hospital setting. As a significant complement to these studies, therefore, our research discusses how representations of patients by nursing practitioners during handover meetings can fulfil institutional requirements while representing patients in compassionate and deinstitutionalised terms.

In taking this approach we are forced from the outset to problematise the focus on efficiency in handover meetings, as the data we analyse comes from a nursing team who are recognised by management for their good practice yet whose handovers are characterised by a large amount of non-scripted talk (NST). Rather than assuming a priori, therefore, that such talk is a distraction, we consider the various goals such NST serves and, for the purposes of the current paper, we focus on instances of what we term compassion talk (CT). We define this as those representations of third parties that express and are liable to evoke recognition of the humanity of those they represent and a desire to ameliorate their suffering.

After providing a brief overview of literature on handovers and on compassion in medical discourse, we describe the pragmatic functions that characterise CT before analysing three interactive sequences from nursing handovers in which CT occurs. These analyses reveal not only how $\mathrm{CT}$ arises spontaneously in such digressions but also how it is successfully utilised and managed by experienced senior nurses. We conclude with a discussion of the contribution such naturally arising talk makes to nursing as a community of practice (Wenger 1998), in contrast to the 'coerced or rule-bound' approaches criticised in the wake of the Mid-Staffs crisis (Royal College of Psychiatrists 2015: 12).

\section{Literature review}

Here we provide a brief overview of previous work on communication in medical handovers, before discussing the role of compassion in medical encounters.

\subsection{Non-scripted talk in handover settings: A problem to be solved or a useful contribution?}

Communication studies on scheduled handover meetings are in agreement that their primary function is the transfer of key medical information from outgoing to incoming staff in a comprehensive and comprehensible manner. They therefore stress the importance of adhering to standardised information-giving formats (e.g. Bomba and Prakash 2005; Budd et al. 2007). These promise to enable and enhance intra- and cross-disciplinary communication by focusing the attention on a

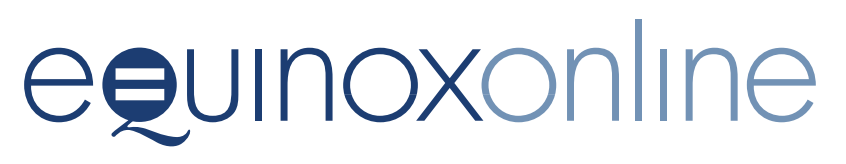


limited set of important facts that can be understood by both outgoing and incoming staff. In a situation where handover information is passed across professional divides, Thakore and Morrison (2001) and Budd et al. (2007) have pointed to the frustration felt by both sides when paramedics hand over to emergency hospital staff, noting that members of both professions agree on the need for a formalised handover structure. Even in instances where handovers occur between members of the same profession, a lack of standardised handover procedures can mean that important information about patients is lost between shift changes, ultimately resulting in the inappropriate administration of treatment by incoming staff (Bomba and Prakash 2005: 68).

In a departure from this focus on standardisation, Eggins and Slade (2012) have recognised the intractably interactive nature of medical handovers, and rather than seeking to eliminate deviations from a set format they focus instead on how unscripted contributions can be managed by the staff involved. However, their recommendations, like the protocols suggested elsewhere, suggest that such digressions from the script have little to add to the functioning of the handover. In contrast, our own position with respect to nursing handovers is that such digressions can potentially serve to fulfil important functions such as team-building and informal apprenticing (Ylänne et al. under review). Moreover, we suggest that the mechanisms recommended by Eggins and Slade can be used to utilise such digressive talk while maintaining the flow of core information. In our analysis, therefore, we consider both how CT emerges as a form of NST within our dataset and how such talk is managed.

\subsection{Compassion in medical contexts}

Durkin et al. (2018: 50) claim that while the term 'compassion' is often used in ethical guidelines for nurses worldwide, it is generally only poorly defined. Nonetheless, many of the points of definition that they identify converge around a view of compassion as (1) what nurses do that diverges from (but complements) their professional tasks (Sweeney 2018: 471; Durkin et al. 2018: 55), and (2) something that happens when patients are related to as people rather than as tasks to be completed (Chambers and Ryder 2016; Straughair et al. 2019). However, interaction in these studies has focused almost exclusively on practitionerpatient relations and on the professional performance of empathy (Pounds et al. 2017) and how this is valued in training and assessment exercises (Atkins and Roberts 2018). In nursing handovers, in contrast, the relationship between the practitioners and the patient is not direct, but is represented by the practitioners in their talk about patients, and this is the focus of the analyses that follow.

\section{Data and methodology}

\subsection{Dataset}

A total of 12 group staff handover meetings (Safety Patient Initiatives or SPIs) were audio-recorded at a hospital in Wales between February and May 2016. These handovers took place at the $7 \mathrm{am}$ and $7 \mathrm{pm}$ shift changes and lasted between 10 minutes and half an hour. The ward on which the data was collected was a Medical Assessment Unit (MAU) that had been identified by the Health Board as performing well on patient safety measures. We also interviewed two senior nurses, in order to present initial findings and to inform our own understandings. Ethical clearance was granted by the authors' university research ethics committee and the health board responsible for our participating hospital. All nurses recorded gave informed written consent and the transcripts were anonymised.

The data was initially transcribed so as to capture only basic conversational features such as turn taking, interruptions and overlapping speech, paralinguistic features such as voice quality and occasional audible non-linguistic features (see Appendix 1 for transcription conventions). This was in accordance with our overall approach to analysing the data, which can be labelled as data-led qualitative analysis. We approached the handovers with no $a$ priori assumptions and, after collecting, recording and transcribing the data, we listened to it and read it multiple times in order to identify recurrent interactional features, with the nature of the observed data motivating the analytical framework adopted for more detailed analysis.

\section{eevunoxonlıne}




\subsection{Analytical framework}

As stated above, one of our most striking observations was the extent to which our data deviated from the standard format of SPIs (see Appendix 2). The first stage of our analysis was therefore to identify and describe what counted as NST. After considering the entire dataset, we defined NST according to three broad and potentially overlapping types: (1) the inclusion of non-essential information; (2) interruptions from members of staff other than outgoing nurse in charge (ONIC in the transcripts); and (3) shifts from the depersonalised and technical medical-institutional voice that typifies these events. In broad terms, the medical-institutional voice objectifies patients as examples of medical conditions or as logistical concerns, describes the patients' conditions in formal, technical and often generalised language and establishes or assumes a divide between staff and patients. This is illustrated in Example 1 (taken from Interaction 2, below; POVA = Protection of Vulnerable Adult procedures).

In the transcripts the nurses' names are pseudonyms and the patients' names have been replaced with FN (first name), LN (last name) and indication of gender $(\mathrm{F} / \mathrm{M})$.

\section{Example 1}

risk of falls is A bay 1 (.) 2 (.) 3 and 4 (1) nobody in B bay (.) $\mathrm{C}$ bay (.) 2 (.) 5 and 6 (1) D bay 3 and 4 (.) and (.) trolleys 1 (.) 2 (.) 3 (.) 4 (.) 6 (.) 9 (.) 12 (2) POVAs and sections the man on trolley 9 in MAU (.) urm (.) [FNLNM] they did a POVA (.) referral for him (.)

In contrast, the 'deviating voice' in these interactions personalises patients in subjective terms, employs informal, non-technical and individualised language and emphasises practical and emotional connections between patients and staff. This is illustrated in Example 2, which follows immediately on from Example 1.

\section{Example 2}

he's an alcoholic gentleman (.) come in with (.) in a complete state of (.) self-neglect (.) apparently he's got a lodger (.) who (1) buys his alcohol and (.) I think (1) looks after his money

Once we had formally identified NST, the next stage was to consider the contribution of such talk and the ways in which it was managed according to the institutional demands of the handover.

One of the key functions of NST that we informally identified was its contribution to creating an ethos of compassion among members of the nursing staff. To follow up on this, therefore, we needed a formal framework for analysing the discursive construction of compassion, as opposed to the practical enactment of compassion that is the focus of previous work. This framework was provided by Lloyd's $(2016,2018)$ analysis of charity appeals and, in particular, how these reduce the perceived distance between viewers and viewed, making it easier for audiences to relate to the experiences of those they view and to react to these in a compassionate manner.

Drawing on concepts from media theory, Lloyd developed a threefold classification of closeness/ distance. The concept of social closeness/distance (Lloyd 2016: 265) refers to the degree to which members of certain groups regularly come into contact with one another socially or, conversely, when groups habitually occupy distinct spaces or use the same physical spaces at different times or in different ways, or when interaction between the groups is of a purely institutional nature. Experiential closeness/distance (derived from Bilandzic 2006) refers to the degree to which characteristics such as gender, ethnicity or nationality are shared and experienced by individuals or groups, while actional closeness/distance refers to the degree to which others are 'real and present' and therefore amenable to positive action. These are all features of social relations but, as Lloyd argues, it is possible to reinforce or deconstruct these boundaries through representations and interactions which create a sense of shared identity and which make positive action seem more or less possible or normal. We therefore classify as CT those representations and interactions that function to reduce distance along any or all of these three parameters.

In order to understand the conditions in which $\mathrm{CT}$ arises and how it operates in specific contexts, we selected for detailed analysis three transcripts with particularly high amounts of NST. Within these we then identified instances of CT, taking an inductive approach that considered the contribution of each utterance as a whole in the context in which it occurred rather than relying on a predefined set of linguistic features. Thus, for instance,

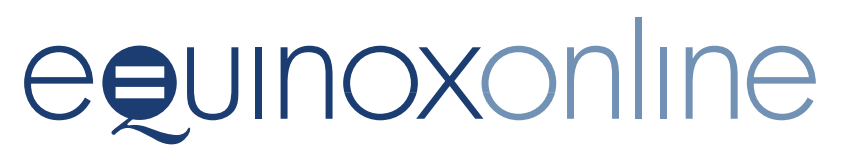


Example 3 (analysed further in Interaction 1, below) illustrates how a reduction in social distance can be achieved through a switch from the institutional representation of patients in terms of bed numbers and full names to a more familiar representation as 'our lady in B1'.

\section{Example 3}

D1 and D4 have both had high BMs (.) so that's a [FNLNM] and a [FNLNM] (2) and our lady in B1 (.) that- had a fall yesterday (.) urm (.) she's been a little bit drowsy today (1)

Example 4 (from Interaction 3), in contrast, illustrates a reduction in experiential distance, as a patient whose behaviour could be evaluated negatively in terms of the potential disruption is represented instead in terms that resonate with shared experiences of childhood and the need for parental tough love.

\section{Example 4}

a young girl who needs to be (.) taken by the scruff of the neck and guided

In Example 5, we see a reduction in the representation of actional distance as two nurses discuss in concrete detail the means by which an incoming patient should and can be treated.

\section{Example 5}

ONIC: they just brought (.) somebody over now (.) put him on the extra trolley for now (1) to do the move and then we'll get her on to (.) number $10($.$) is that$ alright (.)

N3: yeh (.) is that the one [that was just coming through the door]

ONIC: [the dialysis] (.) oh yeh that one that's just come through the door

Talk that represents such events and relationships as possible and normal acts to collapse the sense of distance between the nurses and the patients across these three dimensions. We recognise, however, that these different concepts interact in important and potentially contradictory ways in the functioning of CT. For example, while nurses in their professional roles consistently and necessarily make action in relation to their patients seem possible and necessary (minimising their representational distance from patients), these actions can, in the worst-case scenario highlighted in the RCP report, become routinised and impersonal, treating the patient as a medical case to be dealt with rather than as an individual to be cared for with respect and sensitivity. While reducing actional distance is therefore one aspect of compassionate care, it can be counter-productive unless balanced with a similar reduction in social and experiential distance.

\section{Analysis}

In this section we analyse instances of CT from three separate interactions. We focus in particular on the conditions that give rise to CT, CT's contribution to the ongoing talk and the extent to which CT is successfully controlled and managed by senior nurses.

Interaction 1 clearly demonstrates a marked shift from an institutional voice, characterised by technical terms and with the patients referred to by bay and bed number, to an extended use of informal talk.

Interaction 1: 9 March 2016, 7 pm (14:31-17:00)

1 ONIC: D1 and D4 have both had high BMs (.) so that's a [FNLNM] and a [FNLNM] (2) and our lady in B1 (.) that- had a fall yesterday (.) urm (.) she's been a little bit drowsy today (1) NEWS is okay (.) I think it was a 3 (.) ur:m (.) it does- she had a CT head and it does showuh that she's got a haematoma (.) urm and obviously she did have a raised troponin as well (.) and Emily's aware of that (.) she's been a little bit drowsy today so urm

2 Nurse 2: the C-the CT head was that from the fall or was that previous

3 ONIC: from the fall (1)

4 Nurse 2?: oh (?)

5 ONIC: oh nasty [she (?) aw she went down]

$6 \quad\left[(?)^{\circ}\right]$

7 Nurse?: didn't she

8 ONIC: yeh (.) blood everywhere (.) and was surpri--like you said I was surprised to see (.) it was a tiny little cut (.) on her head like that but it just started to come out- like that (.) I haven't actually put my head in today to see her (2) hm (1) ur:m (.) and we've got a d- a gentleman on uh (.) trolley 10 (.) urm (.) he's going to go down to UHW now (.) [FNLNM] (.) so (.) what we've done (.) 'cause we- we didn't think we were going to get a crew (.) they've been holding 9 crews over in A and E (.) so I said well if one of them can take (.) that gentleman down to UHW (.) then you can have trolley

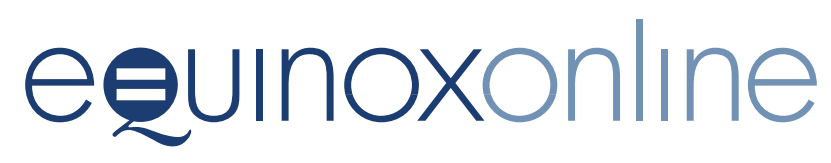


$£ 10 £$ (1) so they just brought (.) somebody over now (.) put him on the extra trolley for now (1) to do the move and then we'll get her on to (.) number 10 (.) is that alright (.)

9 Nurse 3: yeh (.) is that the one [that was just coming through the door]

10 ONIC: [the dialysis] (.) oh yeh that one that's just come through the door yeh so [she's (?)]

11 Nurse 3?: [so she's goi]ng to urm (.) dialysis

12 ONIC: ye:h (.) um trolley 10 (.) yeh (.) urm (.) patients with pressure ulcers we've got trolley 1 [FNLNM] (.) we've got- He's on a (.) rental air mattress this gentleman ur:m (.) he's had medical photography done today (.) an:d refer to TBN

13 Nurse 2?: ((is that the one with the lumps))

14 ONIC: ye::h (1) they're nasty (.)

15 ?: $\quad \mathrm{I} \mathrm{know}^{\circ}$

16 ONIC: but they should have been done (.) they should have been done Monday or (.) I think on a Monday (.) or at least referred ye- yesterday but (.) they didn't so we've done it today (.) ur:m (1) and he's got this nasty eczema as well which (.) is obviously not helping (1) it's urm-Yeh that's him (.) ur:r trolley 12 then (.) she's got a grade $2($.$) to her sacrum (.) and trolley$ 13 (.) she's just red around her groin area

At first glance this lengthy example of NST appears to have been initiated by Nurse 2's interruption from the floor, which is a question posed in a medical voice (turn 2). However, on closer analysis, we see that this interruption has been 'invited' by the ONIC, who has switched from a medical to a social/interpersonal voice during turn 1 and goes as far as to refer to a nurse by her first name ('Emily'). This shift is initially signalled through a change in reference from the patients as bed numbers ('D1 and D4 have both had high BMs') to referring to a specific patient as the occupant of a bed ('our lady in B1'). We can see this shift as in some way deinstitutionalising the patient and so reducing the social distance between the nursing staff and the patients. This reduction in social distance is marked both through the use of the inclusive determiner 'our', which identifies the lady as an individual under the nurses' responsibility at the level of the professional team, and through the use of the term 'lady', which evokes a more personal relationship than alternative terms such as 'patient'.

This shift in role in Interaction 1 is also indicated by the use of hedges and non-medical terminology as in 'obviously', 'a little bit drowsy' (repeated twice in turn 1) and 'I think it was a 3'. The format of the SPI and the paperwork that feeds in and out of it represent patients in depersonalised and standardised terms, thus presenting information with a high degree of certainty and thereby limiting the nurses' range of potential responses. In contrast, the hedging here reduces the actional distance between the nurses and this specific patient by bringing the patient's condition and care requirements out of the realms of abstraction and into the real and present. This opens up areas for negotiation and discussion amongst the nursing staff as they consider what is possible, likely, difficult or even surprising (turn 8 ) in the care of this patient.

When ONIC confirms Nurse 2's question regarding the fall in turn 3 , one of the nurses (probably Nurse 2) reacts using the expressive discourse marker 'oh', which indicates a certain degree of surprise or unexpectedness. This opens up space for an elaboration on the previous information. ONIC responds to this reaction by describing the fall in non-medical terms: assessing the fall as 'nasty', using exaggerations ('blood everywhere') and recounting her own reaction to the source of the bleeding ('I was surprised to see'). The extract, therefore, also demonstrates a reduction in social distance through the familiarity with which ONIC closes her account of 'our lady's' fall, saying 'I haven't actually put my head in to see her today' - a move which represents the nurse and the lady as not only within the same institutional space, but as interactants within the same social activity.

Following this digression, we see how ONIC, after a short pause preluding a shift in voice, reorients her talk explicitly to ward management as she discusses the movements necessary to accommodate the lady and other patients (turns 8-15). Despite this shift, the talk retains elements of $\mathrm{CT}$, with the patient being referred to three times as a 'gentleman' (turns 8 and 12), and everyday language still being used for medical conditions ('lumps' in turn 13 and 'nasty' in turn 14). There is also a further reduction in actional distance as ONIC, Nurse 3 and Nurse 2 interact to confirm the patients' identities (turns 9 and 10) and treatments (turn 11) in relation to the material context of the ward itself. Turn 11 could also be seen as a reduction in social distance, as the patient is now connected to the network of interactions of

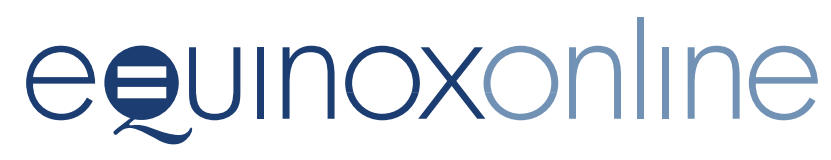


the nursing team rather than the hospital as an institution.

Intersecting with these turns, however, we see ONIC gradually steer the talk back to the core function of the SPI. In turn 12, she resumes the itemisation characteristic of the SPI ('patients with ulcers we've got trolley 1') and, while she allows the further interruptions seen in turns 13 and 15, responding with reduced actional and experiential distance in turn 14 and the beginning of turn 16 ('they should have been done on Monday', 'nasty eczema'), she marks the transition back to the standard scripted format through the pairing of a summative ('yeah that's him') and an explicitly marked resumption ('ur:r trolley 12 then'). From here until the end of the SPI session (which continues for some 15 lines beyond the included extract) ONIC retains her institutional voice and there are no further interruptions.

On the evidence of this interaction, then, the highly negative characterisation of deviations only as communicative problems appears to be overstated. The interaction serves a positive purpose in simultaneously provoking compassion for the patient and fostering affiliation between the nurses as they share their emotional responses to events while ONIC remains in control of the digressions and is capable of bringing the talk back on track as she sees appropriate.

Interaction 2 demonstrates even more clearly the skill with which lead nurses weave between a bare institutional voice and an informal voice inviting compassion talk in order to elaborate on the specific problems and needs of particular patients.

Interaction 2: 11 May 2016, 7 am (2:23-3:50)

1 ONIC: D bay bed 1 [FNLNM] (1) and trolley three in MAU [FNLNM] (1) ur:r we've had a fall (.) the lady in A bay bed 4 [FNLNF] (.) urm woke up (.) was a bit disorientated (.) got out of bed to try and go to the toilet and (.) fell over with her drip stand (.)

2 ?: $\mathrm{Oh}$

3 Nurse 4: (she) okay

4 ONIC: ye:h she's okay (.) she's just a bit shaken she's ninety odd (.) God love her (.) she was sat on the floor (.) bewildered (.) apologising (.)

5 ?: a:ww

6 ONIC: poor thing (.) ${ }^{\circ}$ but she's fine ${ }^{\circ}($.$) risk of falls is A$ bay 1 (.) 2 (.) 3 and 4 (1) nobody in B bay (.) C bay (.) 2 (.) 5 and 6 (1) D bay 3 and 4 (.) and (.) trolleys 1 (.) 2 (.) 3 (.) 4 (.) 6 (.) 9 (.) 12 (2)

[(( shuffling of paper $))]$

7 ONIC: POVAs and sections the man on trolley 9 in

MAU (.) urm (.) [FNLNM] they did a POVA (.) referral for him (.) he's an alcoholic gentleman (.) come in with (.) in a complete state of (.) self-neglect (.) apparently he's got a lodger (.) who (1) buys his alcohol and (.) I think (1)

8 ?: oh no (.) love him

9 ONIC: he knows about it

10 Nurse 1: who's done the POVA then-

11 ONIC: A [and E]

12 Nurse 1: [A and E] (.) okay

In turn 1, ONIC details a fall, in accordance with the requirements of the standard SPI procedure. In doing so, however, she deviates from the norm in providing not just the bay and bed number but also personalising the patient ('the lady in A bay bed 4'). She follows this up in providing details of the fall in terms that highlight the lady as feeling emotions ('was a bit disoriented') and displaying agency ('got out of bed to try and go to the toilet'). This very marked personalisation invokes empathetic responses from the incoming nurses in the form of a token of surprise ('oh' in turn 2) and a check that the lady is 'okay' (turn 3). ONIC confirms the lady is okay but provides more details of her distress ('bit shaken', 'sat on the floor bewildered apologising') and increases the empathetic load ('she's ninety odd God love her'). She then closes the digression with a summative 'poor thing but she's fine' and resumes her institutional SPI voice as she completes the overview of the beds. Up to this point in the interaction we can see how ONIC digresses from the strict SPI format both to reduce social distance, as the lady is personalised, and to reduce actional distance, as the details of the lady's accident, her suffering and emotions and her advanced age are made real and present. Most striking, however, is the absolute ease with which ONIC weaves between institutional talk and $\mathrm{CT}$ and manages the contributions from her colleagues.

This is further evidenced in turn 8, when ONIC moves on to 'POVAs [Protection of Vulnerable Adult procedures] and sections.' ONIC opens with a reference to a patient as 'the man on trolley 9', which represents a more humanised version of the standard institutional reference by bed number, and clarifies that he has had a POVA referral. ONIC

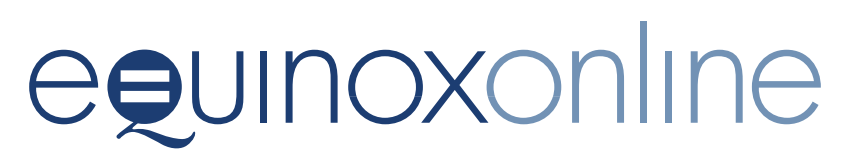


then refers to the man as 'an alcoholic gentleman', a phrase which simultaneously signals his medical condition while indexing respect, as a prelude to describing him as an individual with a back story (turn 8). In contrast to her description of the previous lady, ONIC highlights here the man's lack of agency ('self-neglect', 'he's got a lodger who buys his alcohol and looks after his money'), drawing an empathetic 'oh no love him' (turn 9) and a quick exchange about who is taking care of him (turns 11-13). Through her digression, then, it would appear that ONIC has not only reduced the social distance between the staff and the patient, through the personalisation strategies, but also the actional distance between them, in presenting a potentially difficult patient not as a problem to be managed but as someone in need of an additional kind of care and attention.

In Interaction 3 we see a similar emergence of compassionate talk about an individualised and potentially problematic patient. In this case, however, an incoming nurse presents a negative, albeit humorous, picture of the patient, which ONIC has to manage in order to maintain empathy for the patient and to represent her actions in a non-judgmental light.

\section{Interaction 3: 3 February 2016, 7 pm (16:26-17:50)}

1 ONIC: over on MAU then you've got trolley 6 (.) 7 (1) and $9($.$) and then we've got 34$ and $5($.$) and 11$ 12 and 13 (.) no absconds or self-discharges as yet but urm (.) a young girl in A1 [FN?] (.) urm (2) she just- seems to spend more time off the ward than she's (.)

2 ?: Hmm

3 ONIC: on (1) urm (1) no drug errors or clinical incidents (.) [cause for concern-]

4. Nurse 1: [she's urm (.) pinched] as well

$\begin{array}{lll}5 & & {[\mathrm{hm}]} \\ 6 & \text { ONIC: } & \text { Uh }\end{array}$

7 Nurse 1: she's [pinched]

8 ONIC: [yeh but] what it is is (.) urm with her

9 [ (.) she's a] young girl= [she's the $\left.(?)^{\circ}\right]$

10 Nurse 1: [she's ${ }^{\circ}$ pinched $^{\circ}$ yeh]

11 ONIC: [=that I--. I thought] it was that she'd- [she'd been urm acq] uiring things off patients=

$12 *$ was the (?)]

[that she

13 ONIC: $[=$ on the ward $]()=$.

14 [Eacquiring $£$ ]

15 ONIC: but it wasn't-

$16-$ o [kay]
17 ONIC: [ she] was going outside (.) into shops (.)

18 Nurse 1: o::h

19 ONIC: and taking things and sell [ing them ]

20 [D4 something (?)]

21 oh-

22 [-yeh she can't go to D 4 ] can she

23 [selling them to the patients upstairs]

24 Nurse 1: gosh (.) [that's--].r[eally ] like [entrepreneurial ]

25 [really] (.) [goh ]

26 ONIC?: [she's got the order (?)]

$27 \quad$ ((laughing))

$28 \quad$ the order $£$

29 ((laughing))

30 ONIC?: she got--. I got to be hones- s- say--. in all fairness [(.) she's got- (.)]

31 Nurse 1: [she's got a lovely watch]

32 ((laughing))

33 ONIC: she's got a--. she's urm (1) got a sort of like a lot of underlying problems-

34 Nurse 1: -has she-

35 ONIC: yeh:h (.) it think I overheard her talking to one of the patients and her mum died about four five years ago

36 Nurse 1: Aww

$37 \quad[\mathrm{aww}]$

38 ONIC: [I think] she's a young girl who needs to be (.) taken by the scruff of the neck and guided (.) [you] know

39 Nurse 1: [yeh] yeh (2)

40 ONIC: but that's where the vi--I - they've only given me 3 cause for concerns out of (.) there's quite a few patients on the ward (.) but they've only (.) given me like 3 cause for concerns at the moment (.) gentleman in (.) A bay [FN urm LNM] is it (.)

In Interaction 3 it appears to be an incoming nurse, Nurse 1, who initiates the interruption to the standardised SPI format when, in turn 4, she offers additional information about a patient and even talks over ONIC. Nonetheless, as with Interaction 1, we can see that the interruption was to some extent invited by ONIC when, in turn 1, she reduces the social distance between the nurses and the patient, switching from metonymic reference to patients in terms of the trolleys they currently occupy to more personal terms for one particular patient ('a young girl in A1'). The information ONIC offers about this patient also indicates that she has switched from her medical voice to a more personal voice, indexing a social rather than institutional relationship with the patient. After a minimal response in turn 2 ('hmm'), which perhaps opens the conversational floor for another interjection, Nurse 1 interrupts ONIC in turn 4 to shift the topic back to the previous patient.

\section{eevunoxonlıne}


Despite ONIC's switch in voice in turn 1, the additional information provided about the patient by Nurse 1 seems to be considered by ONIC as inappropriate and we see multiple examples of overlapping speech as ONIC reorients Nurse 1's negative, if humorously intended, representation of the young girl as a thief towards a more compassionate interpretation. From turn 8 , ONIC provides a justification for the patient's behaviour by highlighting mitigating circumstances, such as her youth (turn 8 ) and her problematic background (turn 33).

What is most striking here is how ONIC manages the development of the NST, rather than curtailing it, so as to steer it towards an evaluation of the girl as having 'underlying problems' (turn 33) and as someone "who needs to be taken by the scruff of the neck' (turn 38) as 'her mum died about four or five years ago' (turn 35). As an instance of $\mathrm{CT}$, this example can be analysed simultaneously as a reduction in social and experiential distance. In representing the young girl as a wayward daughter, ONIC brings her into a non-professional relationship with the nurses, thus reducing the social distance between them, while also creating an experiential bond - though, in this case, this is an imagined relationship in which the nurses have to position themselves as caring mothers with difficult daughters of their own, or as the troubled girls they may once have been.

This extract illustrates a further function of digressive talk and the importance of managing rather than curtailing interruptions as, in working through and reorienting Nurse 1's anecdote, ONIC opens up a space for the nurses to air their troubles and grievances within a supportive team environment, so reaffirming their membership of a community of practice.

\section{Discussion: Digressions, compassion talk and nursing as a community of practice}

Communities of practice (Wenger 1998) are bounded groups of people coming together around a common purpose, with various actors interacting in a recognisable way according to their status and roles within that community. Nursing has traditionally been thought of as such a community; however, more recently, and particularly as an effect of the changes to hospital management systems outlined at the start of this article, it has been claimed that all hospital workers instead belong to multiple communities of practice whose activities intersect and overlap. Interactions between and across professions in such Multidisciplinary Teams are now a standard feature of hospital organisation at all levels. At each of these professional intersections there are sets of expectations and requirements to which members orient their actions, and there are appropriate means of communication, including pro formas and other documents, which circulate both within the limits of the ward and the hospital and beyond in different ways.

This is not to say, however, that professionals do not have a core community of practice with which they primarily identify. As Candlin and Candlin (2007: 264-265) put it, despite 'subscribing to' multiple and overlapping communities of practice, nurses retain 'a personal centre' around which they are 'bound, individually and together, not by the institutions of medicine, nursing, or by bureaucracy, but by altruistic caring, and the desire to meet human needs.' Furthermore, as suggested earlier, and highlighted in the RCP document, compassion - and by extension nursing as a community of practice - embraces both the nurses and those in their care as members of a single community. These ideas are well captured in an interview we carried out with two of the senior nurses from the unit, as shown in Interview Extract 1.

Interview Extract 1: (Nurses 1 and 2, Hospital Cafeteria, 19 October 2016)

Nurse 1: [FN] and I are both passionate about this unit, you've probably gathered that and we care (.) Obviously about the patients but we care about our staff as well

Within this community of practice, the bonds between the nurses, driven by a shared sense of vocation, are binding - despite the potentially ambivalent status of the senior nurses somewhere between being practitioners and part of the management (Interview Extract 2)

Interview Extract 2: (Nurses 1 and 2, Hospital Cafeteria, 19 October 2016; Res. 3 = Researcher 3).

Nurse 1: I wouldn't--. we wouldn't ask them to do anything we wouldn't do ourselves

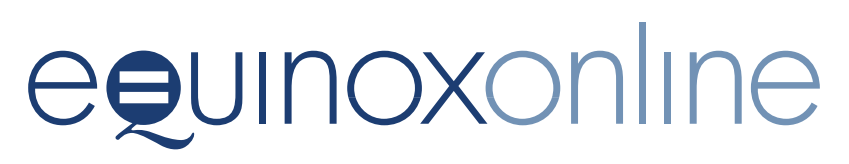


Res. 3: yeh and I think (.) whereas in some organisations the senior management are so separate from the workers that--. so the fact that you do go out and do anything that they would do and more

Nurse 1: well we're nurses (.) you know, that's what we came into nursing for

At the nursing handover meetings we attended there were up to 15 people in a room measuring about $12 \times 8 \mathrm{ft}$. This was indeed a 'crowded space', but not in Iedema's (2007: 9) sense of multiple role sets converging; rather, as these extracts show, this was a space where a unitary team was able not only to meet the institutional requirements in place to ensure safe treatment of patients, but to reaffirm its identity as such and to digress from institutionally ordained scripts and practices. This enabled those present to reground their practices according to the demands and expectations of their core identities as nurses and the emphasis on care and compassion that defines nurses as a community of practice.

\section{Conclusion}

Previous literature on nursing handovers has stressed the importance of the concise and accurate transfer of medical information between practitioners and has, therefore, treated interruptions to the ordinary flow of such information as, at best, digressions to be managed away or, at worst, as potentially dangerous disruptions. There is a need, therefore, to proceed with extreme caution in suggesting that practices that deviate from this goal might contribute to making handovers safer. We note, however, the concern of the Royal College of Psychiatrists $(2015: 2)$ that a focus on the procedural aspects of medical practice at the expense of all else runs the danger of creating the 'shackles of routines and ritual, which hinder flexible, individualised and creative delivery of patient-centred care', and may thus dampen morale, act as constraints on compassionate care and, in extreme cases such as the Mid-Staffs crisis, seriously undermine patient safety.

Our goal in this paper has not been to advocate for one practice over another, but to provide analyses of nursing practice that can be used to inform discussion. To this end, we have demonstrated, firstly, that representations of patients in ways that express or are likely to evoke compassion
- what we have called 'compassion talk' - can arise organically in nursing handovers in the form of non-scripted talk; and, secondly, and in contrast with suggestions from the existing literature, that experienced nurses are able to manage NST so as to maintain the efficient transfer of critical information. This is in no way to deny the existence of counter-examples where NST is non-productive, unnecessarily digressive and ill-managed. The goal of the paper, however, has been to demonstrate that this need not always be the case and to open up discussion of the positive contributions of NST, the dangers of closing it off altogether and the existing skills of senior nursing staff in managing such talk.

Given the emergence of such skills despite the lack of training, this would suggest that senior management needs to recognise the existing working practices of high-performing staff and, rather than imposing a top-down approach that is 'coerced or rule-bound' (Royal College of Psychiatrists 2015: 12), that they could draw on this existing experience as a model for future practice. As the RCP report (Royal College of Psychiatrists 2015: 6-7) observes:

Even experienced practitioners [...] can learn from observing the practice of those recognised to be experts in compassion [...]. An environment in which all seek to be role models and to learn from role models is likely to be one that facilitates compassionate care.

Taking this more positive view of non-scripted talk, the extracts analysed above demonstrate how senior nurses open up spaces for their team to redefine themselves as members of a community of practice, temporarily removed from the wider environment in which they must continuously 'subscribe to' alternative communities of practice (Candlin and Candlin 2007: 264), and to re-establish their core identity as providers of compassionate care within a highly institutionalised space.

\section{Appendix 1:Transcription conventions}

[ overlapping talk begins

] overlapping talk ends

(.) pause, less than half a second

(1) pause in seconds

wo:: elongation of previous sound

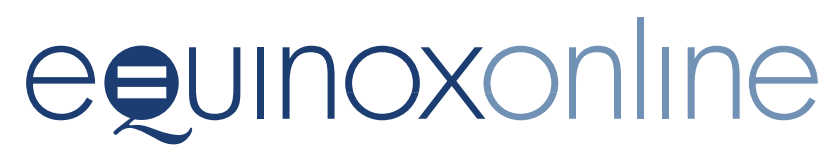


wo-- abruptly ended, cut off sound

(()) contextual information

... lines of transcript omitted

$£ \quad$ smiley voice

- talk noticeably quieter $^{\circ}$

$\begin{array}{ll}\text { FN } & \text { first name } \\ \text { LN } & \text { last name } \\ \text { F } & \text { female } \\ \text { M } & \text { male }\end{array}$

M male

\section{Appendix 2: SPI form}

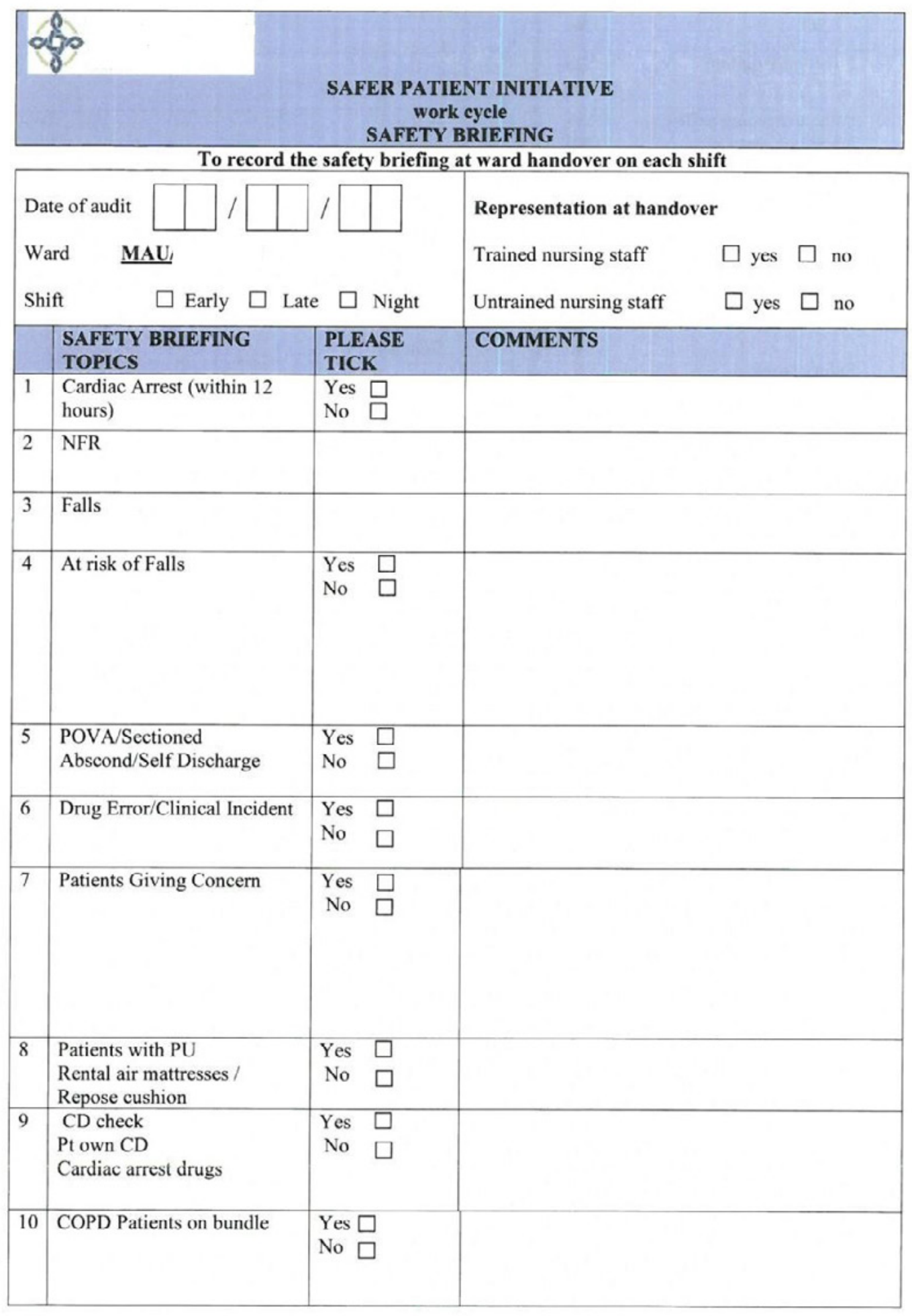

\section{eøuınoxonlıne}




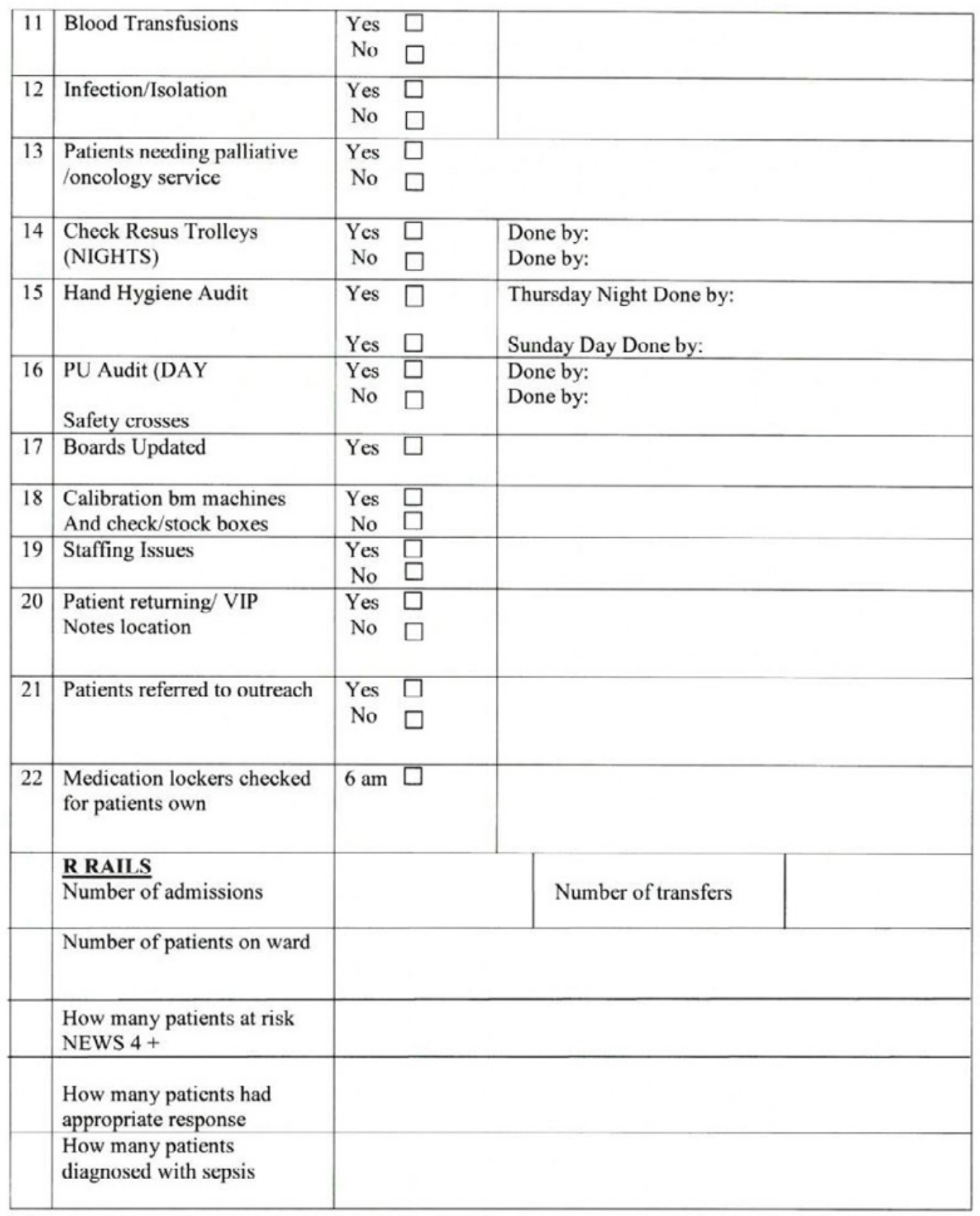

Briefing by Signed

(Print name)

\section{DONT FORGET CANNULA /CATHETER BUNDLES}

\section{Acknowledgement}

We would like to thank our colleague, Lisa El Refaie, for some extremely helpful and insightful comments on earlier drafts.

\section{References}

Atkins, Sarah and Celia Roberts (2018) Assessing institutional empathy in medical settings. Journal of Applied Linguistics and Professional Practice 13 (1-3): 11-33. https://doi.org/10.1558/japl.31861 
Bilandzic, Helena (2006) The perception of distance in the cultivation process: A theoretical consideration of the relationship between television content, processing experience and perceived distance Communication Theory 16 (3): 333-355. https:// doi.org/10.1111/j.1468-2885.2006.00273.x

Bomba, David T. and Robert Prakash (2005) A description of handover processes in an Australian public hospital Australian Health Review 29 (1): 68-70. https://doi.org/10.1071/AH050068

Budd, Henry R., Lawrence M. Almond and Keith Porter (2007) A survey of trauma alert criteria and handover practice in England and Wales Emergency Medicine Journal 24 (4): 302-304. https://doi.org/10.1136/emj.2006.038323

Campbell, Denis (2013) Mid Staffs hospital scandal: the essential guide. The Guardian, 6 February. Available online: https://www. theguardian.com/society $/ 2013 / \mathrm{feb} / 06 / \mathrm{mid}$ staffs-hospital-scandal-guide

Candlin, Sally and Christopher N. Candlin (2007) Nursing through time and space: Some challenges to the construct of community of practice. In Rick Iedema (ed.) The Discourse of Hospital Communication: Tracing Complexities in Contemporary Health Care Organizations, 244-267. Basingstoke, UK: Palgrave. https://doi.org/10.1057/ $\underline{9780230595477 \_12}$

Chambers, Claire and Elaine Ryder (2016) Compassion and Caring in Nursing. London: Routledge.

Durkin, Mark, Russell Gurbutt and Jerome Carson (2018) Qualities, teaching, and measurement of compassion in nursing: A systematic review. Nurse Education Today 63: 50-58. https://doi. org/10.1016/j.nedt.2018.01.025

Eggins, Suzanne and Diana Slade (2012) Clinical handover as an interactive event: Informational and interactive communication strategies in effective shift-change handovers. Communication and Medicine 9 (3): 215-227. https://doi.org/ 10.1558/cam.v9i3.215

Francis, Robert (2013) Report of the Mid Staffordshire NHS Foundation Trust Public Inquiry. London: HMSO. https://doi.org/10.1111/tme.12032

Iedema, Rick (2007) Communicating hospital work. In Rick Iedema (ed.) The Discourse of Hospital Communication: Tracing Complexities in Contemporary Health Care Organizations, 1-17. Basingstoke, UK: Palgrave. https://doi. org/10.1057/9780230595477_1

Lloyd, Harriet (2016) Pity, mass media and social scales. In Jaspal N. Singh, Argyro Kantara and
Dorottya Cserzo (eds) Downscaling Culture, 225-279. Newcastle: Cambridge Scholars.

Lloyd, Harriet (2018) The myth of giving as good: Charitable giving represented as an end in itself. Discourse, Context and Media 25: 122-131. https://doi.org/10.1016/j.dcm.2018.04.005

Pounds, Gabrina, Charlotte Salter, Mary Jane Platt and Pauline Bryant (2017) Developing a new empathy-specific admissions test for applicants to medical schools: A discourse-pragmatic approach. Communication and Medicine 14 (2): 165-180. https://doi.org/10.1558/cam.31522

Royal College of Psychiatrists (2015) Compassion in Care: Ten Things You Can Do To Make a Difference. Faculty Report GAP/02. London: Royal College of Psychiatrists. Available online: https://www. rcpsych.ac.uk/docs/default-source/members/ faculties/general-adult-psychiatry/general-adultfr-gap-02-compassionate-care.pdf

Straughair, Colette, Amanda Clarke and Alison Machin (2019) A constructivist grounded theory study to explore compassion through the perceptions of individuals who have experienced nursing care. Journal of Advanced Nursing 75 (7): 15271538. https://doi.org/10.1111/jan.13987

Sweeney, Cynthia Divens (2018) Compassion: A critical link in extraordinary care for patients and families. Journal of Nursing Administration 48 (10): 471-473. https://doi.org/10.1097/NNA. $\underline{0000000000000653}$

Thakore, Shobhan and William Morrison (2001) A survey of the perceived quality of patient handover by ambulance staff in the resuscitation room. Emergency Medical Journal 18 (4): 293-296. https://doi.org/10.1136/emj.18.4.293

Wenger, Étienne (1998) Communities of Practice: Learning, Meaning, and Identity. Cambridge: Cambridge University Press. https://doi.org/ $\underline{10.1017 / C B O 9780511803932}$

Ylänne, Virpi, Michelle Aldridge-Waddon, Tereza Spilioti and Tom Bartlett (under review) A Critical evaluation of multiple roles and goals in shift-change nursing handovers. A case study: 'We do a lot really, don't we?'

Harriet Lloyd gained her PhD from Cardiff University in 2017. Her doctoral project used multimodal discourse analysis to examine talk and television representations of disadvantage in the UK. She has since worked as a researcher in projects on television representations of elections, devolved politics and industrial disputes, as well as intercultural communication

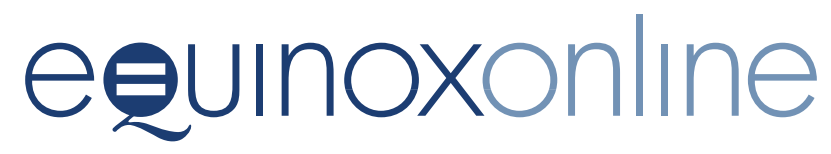


and nursing handovers. She has lectured and supervised research at Cardiff University, University of the West of England, Middlesex University and University College London. She currently works as a Welsh Government social researcher. Address for correspondence: Centre for Language and Communication Research, ENCAP, John Percival Building, Colum Drive, Cardiff CF10 3EU, UK. Email: lloydhr1@cardiff.ac.uk

Tom Bartlett is Professor of Functional and Applied Linguistics at the University of Glasgow and Honorary Professor of Language and Communication Research at Cardiff University. His research interests are systemic functional linguistics and discourse analysis. He is the co-editor (with Gerard O'Grady) of The Routledge Handbook of Systemic Functional Linguistics (2017). Address for correspondence: 12 University Gardens, Glasgow, G12 8QH, UK. Email: tom.bartlett@glasgow.ac.uk

Michelle Aldridge is Reader in Language and Communication at Cardiff University. Her research interests focus on the communicative abilities and experiences of vulnerable people including children and adults with a communication disorder. She has published widely in peer-reviewed journals such as Applied Linguistics Review, International Journal of Speech, Language and the Law, Text E Talk and $W O R D$. Address for correspondence: Centre for Language and Communication Research, ENCAP, John Percival Building, Colum Drive, Cardiff CF10 3EU, UK. Email: aldridgem@cardiff.ac.uk
Tereza Spilioti is Reader in Language and Communication at Cardiff University. Her research interests focus on social interaction and discourse in media and professional communication. She has published widely in peer-reviewed journals (Applied Linguistics Review; Discourse, Context E Media, Pragmatics and World Englishes) and has edited collections such as The Routledge Handbook of Language and Digital Communication (2016, Routledge) and Style, Mediation, and Change: Sociolinguistic Perspectives on Talking Media (2017, Oxford University Press). Address for correspondence: Centre for Language and Communication Research, ENCAP, John Percival Building, Colum Drive, Cardiff CF10 3EU, UK. Email: SpiliotiT1@cardiff.ac.uk

Virpi Ylänne is Senior Lecturer in Language and Communication at Cardiff University. Her research focuses on discourse, image and identity in areas of ageing as well as institutional talk. She has published widely in journals such as Discourse Studies, Journal of Sociolinguistics, Journal of Communication, Ageing and Society, Text and Talk and others, and edited Representing Ageing: Images and Identities (2012, Palgrave). She is currently preparing an edited volume on media and ageing. Address for correspondence: Centre for Language and Communication Research, ENCAP, Colum Drive, Cardiff University, Cardiff, CF10 3EU, UK. Email: Ylanne@cardiff.ac.uk

\section{eevunoxonlıne}

